\title{
Social Capital and Quality of Life among University Students of Yasuj, Iran
}

\author{
Amir Bastaminia ${ }^{1}$, Omid Fakhraie ${ }^{2}$, Mohammad Alizadeh ${ }^{3}$, Azam Bani Asadi ${ }^{4}$, Maryam Dastoorpoor ${ }^{5}$ \\ ${ }^{1} \mathrm{PhD}$ Student in Geography and Urban Planning, Department of Geography, School of Humanities, University of Yazd, \\ Yazd, Iran. \\ ${ }^{2}$ Master of geographic information system (GIS), Islamic Azad University, Science and Research Branch, Yazd, Iran. \\ ${ }^{3}$ PhD Student in Geography and Urban Planning, Department of Geography, School of Humanities, University of Yazd, \\ Yazd, Iran. \\ ${ }^{4}$ BSc in Public Health, School of Public Health, Kerman University of Medical Sciences, Kerman, Iran. \\ ${ }^{5} \mathrm{PhD}$ Student in Epidemiology, Modeling in Health Research Center, Institute for Futures Studies in Health, Kerman \\ University of Medical Sciences, Kerman, Iran. \\ Correspondence: Maryam Dastoorpoor, Haft Bagh-e-Alavi Street, Campus of Epidemiology and Biostatistics \\ Department, Kerman University of Medical Sciences, Kerman, Iran.
}

Received: September 7, 2016

doi:10.11114/ijsss.v4i11.1920
Accepted: September 28, 2016

Available online: October 12, 2016

URL: http://dx.doi.org/10.11114/ijsss.v4i11.1920

\begin{abstract}
Background: Nowadays, quality of life (QOL) is largely associated with social capital and its components such as groups and networks, trust and solidarity, collective action and social cohesion, where social capital can both lead and improve QOL. The aim of this study was to determine the association between social capital and QOL among university students.

Methods: A random sample of 338 students from University of Yasuj participated in this cross-sectional study in 2016, during 8 months. Data is collected using demographics checklist, Iranian version of WHO Quality of Life-BREF (WHOQOL-BREF), and Onyx and Bullen Social Capital Scale. All statistical analysis is performed using STAT 12.

Results: Mean age of the participants was $24 \pm 3.8$ years (boys 24.9 \pm 4.6 ; girls 23.3 \pm 2.8 ). Students scored highest and lowest on physical health $(69.2 \pm 16.8)$ and environmental health $(51.5 \pm 22.3)$ dimensions of QOL and average score of total social capital scale was $85.5 \pm 12.9$. A multiple linear regression analysis confirmed the significant association between all four health-related dimensions of QOL and social capital $(\mathrm{P}<0.001)$.

Conclusion: According to the results, a higher social capital can be indicative of an improved QOL among university students. Therefore, we may seek to build-up social capital by utilizing strategies such as developing social networking, social interactions, security, trust and sharing among university students.
\end{abstract}

Keywords: Social Capital, Quality of Life, University Students, Yasuj

\section{Introduction}

Nowadays with the advancement and expansion of communities, quality of life of people has become a concern all over the world (Al-Ghafri, 2015). In the early days, in some developed communities, this term was considered to be synonymous with other terms including general welfare, social welfare, social security, and other similar terms. However, over time, the concept of quality of life was extended and covered a wide range of these terms (Fayers and Machin, 2013). Further studies which were conducted on this topic helped to clarify factors and dimensions affecting quality of life; the results of such studies provided a ground for developing economic, social, and cultural plans (Birren et al., 2014). In the majority of studies that have been carried out in the field of quality of life, it has been divided into two main classifications i.e. objective and subjective quality of life (Kikuchi et al., 2011). According to the World Health Organization's definition of quality of life it is defined as an individual's perception of their position in life in the context of the culture and value systems in which they live (Murphy et al., 2015). In fact, it can be stated that an individuals' objectives, expectations, and wishes could influence his / her physical, psychological, and social condition and state (Holtan et al., 2015). 
When an individual has access to basic life facilities and tools such as food, clothing, and housing, fulfills its own goals and desires, and reaches its own expectations, his / her trust in community increases and he / she will becomes prepared to participate in collective actions. With the passage of time, as an individual's social cooperation, participation, and social trust augment, his / her social capital will also increase (Lins et al., 2015).

Social capital is a new concept which was first introduced in 1990 by French and American sociologists like Tocqueville, Bourdieu, and James Coleman. Social capital, similar to human capital (i.e. tools and trainings that enhance an individual productivity), denotes features of a social organization such as networks, norms, and trust which will facilitate coordination and cooperation for obtaining mutual benefits. Social capital is consisted of five main components that are used to measure social capital: voluntary participation, social trust, social activities (collective actions), a sense of belonging and solidarity, and commitment to values. Social capital is one of the items that are recognized by health studies as personal and social factors with an impact on the health of people (Richardson, 1986). Multiple studies, conducted at national and international levels, have shown that the components of social capital, especially social trust, have major effects on people's health which are not justifiable by economic criteria (Helliwell, 2006). This is a proven fact that social capital has a positive correlation with physical and psychological health, social relationships, and environmental health (Scheffler et al., 2008). In fact, social capital could justify differences in health between different communities. In communities where people have higher social capital, there are lower rates of crime and higher levels of quality of life (Masalu and Åstrøm, 2002). Social capital has a clear relationship with a person's position in social networks; in addition, the status of an individual in social networks could affect his / her quality of life (Carpiano and Fitterer, 2014). Additionally, when a person takes more advantage of his / her social relationships, he / she will have an easier path ahead to achieve a higher quality of life which in turn decreases many internal conflicts and concerns. Thus, it leads to higher levels of mental and physical health for the individual and community (Oh et al., 2014). Some studies, including two studies by Sharifian and Fotovat (2012) and Azimi and Edrisi (2007) evaluated the effects of social capital on quality of life among students. In Sharifian and Fotovat's study, which was conducted on students in Shiraz University, it was concluded that three important dimensions of social capital including participation, trust, and, social network had an effect on students' quality of life (Sharifiyan A and Fotovat H, 2012). Azimi and Edrisi conducted a cross sectional study on students in Azad University of Dehaghan in 2010; according to their findings, social trust was recognized as one of the important determinants of social capital which was effective in improving students' quality of life (Azimi L and Edrisi A, 2007).

According to previous studies, high, moderate, and low socioeconomic status the hierarchical system of communities in most cases have a significant effect on social functioning of people. Moreover, they can be effective in the formation of subcultures and social identities (Javaheri, 2007). On the other hand, the differences in socioeconomic classes can affect the quality of life of every group of community. Quality of life is greatly influenced by time and space and it could be diverse in different time periods and geographic locations (Rezvani and Mansourian, 2008). Accordingly, different levels of health, safety, social networks, and other similar factors can affect the quality of life and social capital of people living in different regions (Rezvani et al., 2011). Nevertheless, this issue has not been addressed in many cities. For instance, in Yasuj city in Kohgiluyeh and Boyer Ahmad province a very small number of studies have been conducted on this topic. At the present, citizens and students are faced with various problems in Yasuj city which are mainly due to the lack of proper planning and other problems including non-hierarchical distribution of services to fit the population distribution of Yasuj. In addition, because of the concentration of facilities in some other areas, it seems that citizens and especially students are not benefiting from a desirable level of quality of life (Zarabi and Shahivandi, 2010). Comparing the statistics in Iran with the world shows that our country is home to $1.6 \%$ of students in the world. State University of Yasuj has over 6,000 students. Thus, paying special attention to students' quality of life can be of great importance. Research also has shown that students with a higher level of quality of life usually make the best use of all university services and even facilities located outside their university (Shakhi et al., 2013). Thus, the aim of this study was to determine the relationship between students' social capital and quality of life in the city of Yasuj in 2015. To meet the objectives of this study, we evaluated different indices such as participation in local communities, feeling of trust and safety, work Connections, interactions with friends and neighbors, and other determinants of social capital. Moreover, we assessed the effects of the mentioned factors on four domains of physical health, psychological health, social relationships, and environmental health to determine the overall quality of life of students in state University of Yasuj.

\section{Methods}

\subsection{Study Population and Sampling Method}

This cross sectional descriptive analytical study, which lasted for eight months, was conducted on students in Yasuj University in 2015. As the total number of students was over 6000, Cochran formula was used to determine sample size. According to this formula, the sample size was calculated as 361 persons (error $=5 \%, \mathrm{t}=1.96, \mathrm{p}=\mathrm{q}=0.05$ ) was estimated. 
In this study, 23 subjects did not complete the questionnaire and were excluded from the study. As a result, a total of 338 questionnaires were used for statistical analysis.

The samples were selected via multi-stage cluster sampling method. First, of the six faculties in State University of Yasuj, three faculties of Engineering, Sciences, and Humanities were randomly selected and then from each of the faculties three disciplines were randomly chosen. At the end, of classes hold for each discipline, one was randomly selected and all students in the class were asked to complete the questionnaires.

\subsection{Data Collection Tool}

The required data was collected via using the following tools.

Demographic data checklist: It was used to collect the data about the following items: age, gender (male, female), marital status (single, married, widowed, and divorced), educational degree (Associate diploma, Bachelor, Master, $\mathrm{Ph} . \mathrm{D}$.), total number of years of education that was successfully completed, current location (dormitory, nondormitory), employment status (employed \{1. self-employed, 2. working for government\}, unemployed \{students\}), average monthly individual income, average monthly family income, size of residential place (area of the residential place), current number of family members, home ownership (owner, tenant, other), number of rooms available, length of stay on current location, language spoken at home (Persian, Lorry, other), status of health insurance coverage (yes, no), type of health insurance (Medical Services, Social Security, Armed Forces, Oil and Gas, Health), current chronic disease (Yes, No).

Onyx and Bullen Social Capital Questionnaire: To collect data about social capital in this study we used Onyx and Bullen questionnaire which has 36 questions to assess social capital. Its questions are extracted from the questionnaires developed by American community of social capital, the World Bank, and the Australian Institute of Family Studies. The questionnaire covers eight dimensions including participation in the local community (7 questions), Social Agency, or Proactivity in a Social Context (7 questions), Feelings of Trust and Safety (5 questions), interactions with neighbors (5 questions), family and friends connections ( 3 questions), tolerance of diversity ( 2 questions), value of life (2 questions), and work connections (3 questions) (Bullen and Onyx, 1998). The questions were multiple-choice and scored on a Likert scale ranging from very low (1 point), to low ( 2 points), high ( 3 points), very high (4 points). To obtain the total score, the points obtained for all the questions were summed up. This score ranged from 36 to 144 . The higher the score, the more a respondent would benefit from social capital and vice versa. Validity and reliability of the questionnaire has been already proved via running it on over 1,200 people in five Australian states. According to the results of factor analysis of the questionnaire, which was conducted using varimax rotation, the correlation coefficient was between 0.52 and 0.87 . To confirm reliability, test- retest method was used and the Pearson correlation coefficient was 0.84 which represented an acceptable level of validity and reliability for using the questionnaire in the community and family (Onyx and Bullen, 2000). This questionnaire has been translated and validated in Iran by Moradian et al. Accordingly, this questionnaire was first translated into Farsi and the validity of the translated version was proved by experts and professionals in this field. After confirming the contents of the questionnaire, the questionnaire reliability was studied; as Cronbach's alpha coefficient was calculated as 0.82 , the reliability of the questionnaire was confirmed (Moradian Sorkhkolaee et al., 2013). In this study, we used the questionnaire localized by Moradian et al.

World Health Organization Quality of Life Questionnaire (Iranian version): WHOQOL- BREF is the brief from of The World Health Organization Quality of Life Scale with 100 items (WHOQOL- 100). This questionnaire contains 26 questions. The first and second questions, respectively, are intended to investigate the quality of life in general and the general health status. These two questions do not belong to any of the domains. The other 24 questions determine the status of quality of life in four domains including: A. physical health (7 questions), B. mental health (6 questions), C. social relations (3 questions), and D. environmental health (8 questions). Each item has several options including "never, rarely, sometimes, often, always" or "absolutely disagree, disagree, somewhat agree, agree, absolutely agree" or other similar terms which are scored in a range of 1 to 5 points. The participants obtain a row score of 4 to 20 points in every domain. After obtaining the raw scores of each subscale, they must be converted to a standard score ranging from 0 to 100 in which higher scores indicate better quality of life (Organization, W. H. 1996). World Health Organization Quality of Life Questionnaire is of great popularity and is translated into 40 languages including Persian language and in validated in many countries. Iranian version of the questionnaire was designed by Nejat et al. According to the results of Nejat et al.'s study, Cronbach's alpha coefficient and intraclass correlation values in all domains were above $70 \%$ (Nedjat et al., 2008). In our study was used the standard Persian version of the questionnaire prepared by Nejat et al.

Before completing the questionnaire, the objectives of the study were thoroughly explained to each individual. After obtaining informed consent from volunteers, questionnaires were completed. The collected data were analyzed using STATA software version 12. To analyze the data we used descriptive statistics such as frequency, frequency percentage, mean, and standard deviation. On the other hand, to analyze the research hypotheses we used analytical statistical tests 
including univariate and multivariate linear regression and Pearson correlation coefficient with a confidence interval of $95 \%$ an a significance level of 0.05 . It is worth noting that in order to evaluate independent factors affecting different domains of quality of life, only variables were entered into the linear regression model which had a P-value less than 0.2 in univariate analysis.

\section{Results}

The mean ( \pm standard deviation) age of participants was $24 \pm 3.8$ years (boys: $24.9 \pm 4.6$, girls: $23.3 \pm 2.8$ ). The majority of participants were female (55.3 percent), single (89.1 percent), not living in dormitory (83.7 percent), unemployed (87.6 percent), owner of the residential place (87.6 percent), and covered by health insurance $(80.8$ percent). Considering their education level, the majority of them were undergraduate students ( 89.9 percent). The average monthly income of employed students was $\$ 416(\mathrm{SD}=10,996,310)$. The average size of participants' residential area was 228.4 square meters $(\mathrm{SD}=123.7 \mathrm{~m})$. The mean family size was $6.5(\mathrm{SD}=1.8$ people) with at least 2 members and a maximum of 9 members in the family. The mean length of stay in current residential area was 14.5 years ( $\mathrm{SD}=12.3$ years). Concerning the language spoken in the family, Persian, Lori, and other languages, respectively, were spoken by $5.6 \%, 92.9 \%$, and $1.5 \%$ of the participants' families (Table 1 ).

Table 2 presents the distribution of total social capital and its dimensions. As shown, social agency or Proactivity in a social context had the highest mean score $(17.4 \pm 3.4)$ and value of life had the lowest mean score $(5.3 \pm 1.6)$. The mean score of total social capital was $85.2 \pm 12.9$.

Among the four domains of health-related quality of life, physical health domain $(69.2 \pm 16.8)$ and environmental health $(51.5 \pm 22.3)$, respectively, had the highest and lowest mean scores (Table 3).

The results of Pearson correlation coefficient showed that the total Social capital had a positive and statistically significant relationship with physical health, mental health, and social relationships; the highest correlation was observed in social relationships $(\mathrm{r}=0.4, \mathrm{p}<0.001)$. Moreover, the results of correlation test showed no statistically significant correlation or association between total social capital and environmental health domain $(r=0, p>0.999)$ (Table 4).

Finally, in order to determine the impact of total social capital on the four domains of health-related quality of life (after adjusting for confounding effect of other variables), multiple linear regression model was used. As the results in Table 5 shows, social capital had a significant and positive effect on all the four domains of physical health, mental health, social relationships and environmental health.

Table 1. Distribution of Demographic Variables in Students Participating in the Study $(\mathrm{n}=338)$

\begin{tabular}{ccc}
\hline Variable & Number & Frequency \\
Male & Gender & Percentage \\
Female & 151 & 44.7 \\
& 87 & 55.3 \\
Married & Marital status & \\
Single & 31 & 9.2 \\
Divorced & 301 & 89.1 \\
Widowed & 1 & 0.3 \\
& 5 & 1.5 \\
Associate diploma & Education level & 6.5 \\
Bachelor & 22 & 89.9 \\
Master & 304 & 3.6 \\
& 12 & 16.3 \\
Living in dormitory & Current accommodation status & 83.7 \\
Living out of dormitory & 55 & 12.4 \\
& 283 & \\
Employed & Occupation status & \\
& 42 & \\
\hline & & \\
& &
\end{tabular}




\begin{tabular}{ccc}
\hline Unemployed & 296 & 87.6 \\
Owner & Home ownership & \\
Tenant & 296 & 87.6 \\
Other & 28 & 8.3 \\
& 14 & 4.1 \\
Yes & Current chronic diseases & \\
No & 65 & 19.2 \\
& 273 & 80.8 \\
Yes & Insurance coverage status & \\
No & 273 & 80.8 \\
& 65 & 19.2 \\
\hline
\end{tabular}

Table 2. Distribution of Mean Social Capital and Its Dimensions among the Studied Students

\begin{tabular}{cccccc}
\hline Variable & Number & Mean & Standard deviation & Minimum & Maximum \\
\hline Participation in the local community & 338 & 15.3 & 3.6 & 7 & 27 \\
Social Agency, or Proactivity in a Social & 338 & 17.4 & 3.4 & 7 & 26 \\
Context & & & & & \\
Feelings of Trust and Safety & 338 & 12.1 & 2.8 & 5 & 20 \\
Interactions with peer groups & 338 & 12.9 & 2.9 & 5 & 20 \\
Family and Friends Connections & 338 & 7.8 & 2.3 & 3 & 12 \\
Tolerance of diversity & 338 & 5.8 & 1.7 & 2 & 8 \\
Value of Life & 338 & 5.3 & 1.6 & 2 & 8 \\
Work Connections & 338 & 8.5 & 2.4 & 3 & 12 \\
Total Social capital & 338 & 85.2 & 12.9 & 34 & 121 \\
\hline
\end{tabular}

Table 3. Distribution of Mean Values of Quality of Life and Its Domains among the Studied Students

\begin{tabular}{cccccc}
\hline Variable & Number & Mean & Standard deviation & Minimum & Maximum \\
\hline Physical health & 336 & 69.2 & 16.8 & 10.7 & 100 \\
Mental health & 334 & 67.8 & 17.9 & 12.5 & 100 \\
Social Relationships & 331 & 68.6 & 22.1 & 0 & 100 \\
Environmental health & 334 & 51.5 & 22.3 & 0 & 100 \\
Total quality of life & 336 & 72.6 & 23 & 0 & 100 \\
\hline
\end{tabular}

Table 4. Relationship between the Two Variables of Quality of Life and Social Capital and Their Dimensions among the Studied Students $(\mathrm{N}=338)$

\begin{tabular}{cccccc}
\hline & Physical health & Mental health & $\begin{array}{c}\text { Social } \\
\text { relations }\end{array}$ & $\begin{array}{c}\text { Environmental } \\
\text { health }\end{array}$ & $\begin{array}{c}\text { Total quality of } \\
\text { life }\end{array}$ \\
\hline $\begin{array}{c}\text { Participation in the local } \\
\text { community }\end{array}$ & $0.01(\mathrm{P}<0.001)$ & $0.1(\mathrm{P}<0.001)$ & $0.1(\mathrm{P}<0.001)$ & $0.1(\mathrm{P}<0.001)$ & $0.1(\mathrm{P}<0.001)$ \\
$\begin{array}{c}\text { Social Agency, or } \\
\text { Proactivity in a Social } \\
\text { Context }\end{array}$ & $0.06(\mathrm{P}<0.001)$ & $0.0(\mathrm{p}=0.2)$ & $0.0(\mathrm{p}=0.1)$ & $0.3(\mathrm{P}<0.001)$ & $0.1(\mathrm{P}<0.001)$ \\
$\begin{array}{c}\text { Feelings of Trust and } \\
\text { Pan }\end{array}$ & $0.01(\mathrm{P}<0.001)$ & $0.2(\mathrm{P}<0.001)$ & $0.2(\mathrm{P}<0.001)$ & $0.0(\mathrm{p}=0.7)$ & $0.0(\mathrm{p}=0.1)$ \\
\hline
\end{tabular}




\begin{tabular}{cccccc}
\hline $\begin{array}{c}\text { Safety } \\
\text { Interactions with peer } \\
\text { groups }\end{array}$ & $0.02(\mathrm{P}<0.001)$ & $0.2(\mathrm{P}<0.001)$ & $0.3(\mathrm{P}<0.001)$ & $0.0(\mathrm{p}=0.1)$ & $0.1(\mathrm{P}<0.001)$ \\
$\begin{array}{c}\text { Family and Friends } \\
\text { Connections }\end{array}$ & $0.01(\mathrm{P}<0.001)$ & $0.1(\mathrm{P}<0.001)$ & $0.3(\mathrm{P}<0.001)$ & $-0.2(\mathrm{P}<0.001)$ & $0.0(\mathrm{p}=0.7)$ \\
$\begin{array}{c}\text { Tolerance of diversity } \\
\text { Value of Life }\end{array}$ & $0.02(\mathrm{P}<0.001)$ & $0.3(\mathrm{P}<0.001)$ & $0.3(\mathrm{P}<0.001)$ & $0.2(\mathrm{P}<0.001)$ & $0.0(\mathrm{p}=0.8)$ \\
$\begin{array}{c}\text { Work Connections } \\
\text { Total Social capital }\end{array}$ & $0.03(\mathrm{P}<0.001)$ & $0.4(\mathrm{P}<0.001)$ & $0.3(\mathrm{P}<0.001)$ & $0.0(\mathrm{p}=0.2)$ & $0.2(\mathrm{P}<0.001)$ \\
\hline
\end{tabular}

** $\mathrm{P}$ value less than 0.05 is significant.

Table 5. Evaluation of Effects of Demographic Variables and Total Social Capital on Different Domains of Quality of Life among the Studied Students Using Linear Regression (Enter method)

\begin{tabular}{|c|c|c|c|c|c|}
\hline \multirow[t]{2}{*}{ Model } & \multicolumn{2}{|c|}{$\begin{array}{c}\text { Non-standardized regression } \\
\text { coefficient }\end{array}$} & \multirow{2}{*}{$\begin{array}{c}\text { standardized regression } \\
\text { coefficient }\end{array}$} & \multirow[t]{2}{*}{$\mathrm{t}$} & \multirow[t]{2}{*}{$P$ value } \\
\hline & $\mathrm{B}$ & $\mathrm{SD}$ & & & \\
\hline \multicolumn{6}{|c|}{ First domain of quality of life: Physical health } \\
\hline Fixed value & 83.7 & 13 & & 6.4 & $\mathrm{P}<0.001$ \\
\hline Total Social Capital & 0.2 & 0 & 0.2 & 4.7 & $\mathrm{P}<0.001$ \\
\hline Insurance & -6.8 & 2.2 & -0.1 & -3.1 & $\mathrm{P}<0.001$ \\
\hline Home ownership & -3.5 & 1.3 & -0.1 & -2.6 & $\mathrm{P}<0.001$ \\
\hline Education level & -7.2 & 2.8 & -0.1 & -2.5 & $\mathrm{P}<0.001$ \\
\hline \multicolumn{6}{|c|}{ Second domain of quality of life: Mental health } \\
\hline Fixed value & 29.1 & 6.9 & & 4.1 & $\mathrm{P}<0.001$ \\
\hline Total Social capital & 0.3 & 0.05 & 0.3 & 6.8 & $\mathrm{P}<0.001$ \\
\hline Income & 2.4 & 0 & 0.1 & 2.4 & $\mathrm{P}<0.001$ \\
\hline Insurance & -5 & 2.4 & -0.1 & -2.1 & $\mathrm{P}<0.001$ \\
\hline \multicolumn{6}{|c|}{ Third domain of quality of life: social relations } \\
\hline Fixed value & 17.9 & 12.3 & & 1.4 & 0.1 \\
\hline Total Social capital & 0.4 & 0 & 0.3 & 7.5 & $\mathrm{P}<0.001$ \\
\hline Number of family members & -1.2 & 0.6 & 0 & -1.9 & $\mathrm{P}<0.001$ \\
\hline Current accommodation status & -6.2 & 3 & -0.1 & -2 & $\mathrm{P}<0.001$ \\
\hline Language & 5.2 & 2.2 & 0.1 & 2.3 & $\mathrm{P}<0.001$ \\
\hline \multicolumn{6}{|c|}{ Fourth domain of quality of life: Environmental health } \\
\hline Fixed value & 13.1 & 12.9 & & -1 & 0.3 \\
\hline Total Social capital & 0.1 & 0 & 0.1 & 2.1 & $\mathrm{P}<0.001$ \\
\hline Number of rooms & 2.3 & 0.9 & 0.1 & 2.4 & $\mathrm{P}<0.001$ \\
\hline Gender & 16.6 & 2.2 & 0.3 & 7.5 & $\mathrm{P}<0.001$ \\
\hline Current accommodation status & 18.3 & 2.9 & 0.3 & 6.1 & $\mathrm{P}<0.001$ \\
\hline Language & -5.7 & 2.2 & -0.1 & -2.5 & $\mathrm{P}<0.001$ \\
\hline
\end{tabular}

\section{Discussion}

Everybody is aware of the significance of the concepts of social capital and quality of life among students, because 
solving social problems of this group has been always an important issue for researchers. Many social problems and challenges are rooted in false ways of living, poor quality of life, lack of social interaction, lack of trust, and low level of social capital. In this study, it was tried to investigate and explore the mentioned factors among students and analyze them systematically.

Based on the results of this study, social capital had a positive and significant relationship with quality of life. This means that with increasing the social capital, quality of life improved and vice versa; it is consistent with the results of studies by Rajabi et al. (2014), Sharifian and Fotovat (2012), Rimaz et al. (2014, 2015), Rahmani and Sohrabi (2012), Alizadeh et al (2015), and Berry and Welsh (2010). In addition, Roslan et al. conducted a study on 2500 rural households in Terengganu, Malaysia, and the results showed that social capital not only affects household income but also plays a role in the quality of life of this group of people (Roslan et al., 2010).

To justify this finding it can be said that quality of life is an individual's assessments and perceptions of its one's own life which is influenced by cultural and social value system of every community. This understanding and perception must fit the resources, facilities, and goals of an individual. When the perceptions fit the reality, people will get rid of the primary concerns of life such as thinking about food, shelter, and clothing; instead, they will move toward communication channels and over time they will develop a collective sense of identity, a shared picture of the future, and a positive impression toward their community. As a consequence, they will participate in community decisions. The involvement and participation, life satisfaction, good feelings, along with the utilization of social, economic, and political facilities automatically develop feelings of trust and safety. Trust and community involvement together could result in the formation and escalation of social capital. So it seems that enhancing social network, social trust, and social participation could enhance people's quality of life.

After adjusting for confounding variables including demographic and socioeconomic variables, the results of multivariate linear regression showed that domains of physical health, environmental health, and health-related quality of life had a positive and statistically significant relationship with the Social capital - General. This findings is consistent with the results of studies by Rajabi et al. (2014), Zamanzadeh et al. (2007), Hatami et al. (2010), Gilbert et al. (2013) and Giordano and Lindstrom (2010). From this perspective, social capital in the field of health is mainly focused on the macro level. It motivates people to join groups and participate in community; as a result, it accelerates people's participation in social affairs and thus improves their physical health (Pearce and Davey Smith, 2003).

The adjusted results showed a positive and significant relationship between mental health domain and Social capital General. This finding is consistent with the results of many other studies that have examined the relationship between these two variables, including studies by Kamran and Ershadi (2008), Hatami et al. (2010), Razavizadeh et al. (2013), Poorafkary (2012), Amini Rarani et al. (2011), Tavakol et al. (2012), Soltani and Jamali (2008), and Gilbert et al. (2013). This relationship can be justified on the basis of network theory. Caroline et al. (2000) believe that the existence of social networks act as a buffer against internal stressors, so they provide emotional support, friendships, and opportunities for meaningful social action in the form of social capital. As a result, they have a very important and effective impact on people's self-esteem, increase people's capacity to deal with problems and depression, and eventually cause a feeling of mental health (Kamran and Ershadi, 2008).

There was also a significant relationship between the domain of social relationship and social capital. This finding is in line with the results of studies by Amini Rarani et al. (2011), Ghaempour (2015), and Fooladian (2009). The results of Fooladian's study showed a positive and statistically significant relationship between social capital and the domain of social relationship. It is reported that when social relations are not maintained, they gradually disappear, the mutual and bilateral commitments fade out, and consequently social capital declines (Fooladian, 2009).

Moreover, some studies, including two studies by Burke et al. (2010) and Johnston et al. (2013) investigated the relationship between the social relations and social capital on Facebook network. The mentioned studies have shown a positive and significant relationship between social capital and the use of this network.

Social capital has two dimensions, cognitive and structural. The cognitive dimension of social capital covers the qualitative aspects of social capital and includes several criteria such as values, mutual norms, and trust. It can affect the general concept of health through developing health related norms and behavior such as the control of high-risk behaviors, different types of social protection, and development of informal means of information exchange. While cognitive dimension of social capital is the main factor pushing people into collective action, the structural dimension facilitates this process. Both cognitive and structural dimensions of social capital could improve health and quality of life. They not only increase people's sense of belonging and solidarity, but also lead to an increased level of efficiency, self-esteem, and self-mastery. The positive and significant relationship between social capital and quality of life can be justified by the mechanisms of communication at the family level (intra-group level) and at generalized levels (extra-group level). 


\section{Conclusion}

The results of this study showed that the Social capital - General had a positive and statistically significant relationship with all domains of health-related quality of life including physical health, mental health, social relations, and environmental health. Therefore, it seems that social capital could improve the quality of life through increasing social relations and social inclusion, improving social agency, promoting initiative actions in the social field, and enhancing a Feelings of Trust and Safety. Thus in order to increase the level of social capital among students and ultimately enhance their quality of life, it is necessary to adopt social development policies both in the community and among students; it is also necessary to utilize new social networks and strengthen existing networks, provide a ground for voluntary actions and activities, hold workshops to train people about capabilities and social participation in universities, and provide more suitable facilities on university campus.

\section{Acknowledgements}

Researchers would like to express their thanks to all the students who participated in this study.

\section{References}

Al-Ghafri, H. (2015). Social Drift in Patients Suffering from Alcohol and Substance Related Disorders, Amman, Jordan. (2015). International Journal of Emergency Mental Health and Human Resilience.

Alizadeh, M., Sayyah-Melli, M., Ebrahimi, H., Shishavan, M. K., \& Rahmani, F. (2015). Social Determinants and Reproductive Factors of the Menopausal Symptoms among Women in Tabriz-Iran. Social Determinants of Health, $1,2-8$.

Amini, R. M., Mousavi, M. T., \& Rafiey, H. (2011). Correlation of Social Capital with Social Health in Iran. Social Welfare Quarterly, 11, 203-228.

Azimi, L., \& Edrisi, A. (2007). Social trust factor for the development of society, Proceedings of the Regional Conference on social capital challenges and strategies, Vice Chancellor for Research of Azad university of Dehaghan.

Berry, H. L., \& Welsh, J. A. (2010). Social capital and health in Australia: an overview from the household, income and labour dynamics in Australia survey. Social science \& medicine, 70, 588-596. http://dx.doi.org/10.1016/j.socscimed.2009.10.012

Birren, J. E., Lubben, J. E., Rowe, J. C., \& Deutchman, D. E. (2014). The concept and measurement of quality of life in the frail elderly, Academic Press.

Bullen, P., \& Onyx, J. (1998). Measuring social capital in five communities in NSW: A practitioner's guide, Management Alternatives Pty Limited.

Burke, M., Marlow, C., \& Lento, T. (2010). Social network activity and social well-being. Proceedings of the SIGCHI conference on human factors in computing systems. ACM, 1909-1912. http://dx.doi.org/10.1145/1753326.1753613

Cappiano, R. M., \& Fitterer, L. M. (2014). Questions of trust in health research on social capital: What aspects of personal network social capital do they measure? Social Science \& Medicine, 116, 225-234. http://dx.doi.org/10.1016/j.socscimed.2014.03.017

Fayers, P., \& Machin, D. (2013). Quality of life: the assessment, analysis and interpretation of patient-reported outcomes, John Wiley \& Sons.

Fooladian, A. (2009). A Survey of The Social Capital Amount among The IAUM Students. Quarterly Journal of History of Civilization and Jurisprudence, 6, 87-112.

Ghaempour, M. A. (2015). Social and scientific communications in Sharif University: students' points of view. Quarterly Journal of Research and Planning in Higher Education, 20, 95-144.

Gilbert, K. L., Quinn, S. C., Goodman, R. M., Butler, J., \& Wallace, J. M. (2013). A meta-analysis of social capital and health: A case for needed research. Journal of health psychology, 18, 1385-1399. http://dx.doi.org/10.1177/1359105311435983

Giordano, G. N., \& Lindstrom, M. (2010). The impact of changes in different aspects of social capital and material conditions on self-rated health over time: a longitudinal cohort study. Social science \& medicine, 70, 700-710. http://dx.doi.org/10.1016/j.socscimed.2009.10.044

Hatami, G., Motamed, N., \& Ashrafzadeh, M. (2010). Confirmatory factor analysis of Persian adaptation of multidimensional students' life satisfaction scale (MSLSS). Social Indicators Research, 98, 265-271. http://dx.doi.org/10.1007/s11205-009-9538-2 
Helliwell, J. F. (2006). Well - Being, Social Capital and Public Policy: What's New?*. The Economic Journal, 116, C34-C45. http://dx.doi.org/10.1111/j.1468-0297.2006.01074.x

Holtan, M. T., Dieterlen, S. L., \& Sullivan, W. C. (2015). Social Life Under Cover Tree Canopy and Social Capital in Baltimore, Maryland. Environment and behavior, 47, 502-525. http://dx.doi.org/10.1177/0013916513518064

Javaheri, F. (2007). The study on affecting socio-economic status on university students' attitudes and behaviors.

Johnston, K., Tanner, M., Lalla, N., \& Kawalski, D. (2013). Social capital: the benefit of Facebook 'friends'. Behaviour \& Information Technology, 32, 24-36. http://dx.doi.org/10.1080/0144929X.2010.550063

Kamran, F., \& Ershadi, K. (2008). The relationship between social capital and mental health. Journal of Social Research, 2, 29-54.

Kikuchi, H., Mifune, N., Niino, M., Ohbu, S., Kira, J. I., Kohriyama, T., Ota, K., Tanaka, M., Ochi, H., \& Nakane, S. (2011). Impact and characteristics of quality of life in Japanese patients with multiple sclerosis. Quality of life research, 20, 119-131. http://dx.doi.org/10.1007/s11136-010-9725-2

Lins, K. V., Servaes, H., \& Tamayo, A. (2015). Social capital, trust, and firm performance during the financial crisis. Trust, and Firm Performance During the Financial Crisis (January 26, 2015).

Masalu, J. R., \& Åstrom, A. N. (2002). Social and behavioral correlates of oral quality of life studied among university $\begin{array}{llllll}\text { students in } \quad \text { Tanzania. Acta } & \text { Odontologica Scandinavica, }\end{array}$ http://dx.doi.org/10.1080/000163502762667388

Moradian, S. M., Esmaeil, S. S., Sadeghi, R., Nikooseresht, Z., \& Fard, F. (2013). The relationship between quality of life and social capital among health workers in medical and health network of Rey city in 2012. Razi Journal of Medical Sciences, 20, 69-77.

Murphy, M. E., Holzer, III, C. E., Richardson, L. M., Epperson, K., Ojeda, S., Martinez, E. M., Suman, O. E., Herndon, D. N., \& Meyer III, W. J. (2015). Quality of life of young adult survivors of pediatric burns using World Health Organization Disability Assessment Scale II and Burn Specific Health Scale-Brief: a comparison. Journal of Burn Care \& Research, 36, 521-533. http://dx.doi.org/10.1097/BCR.0000000000000156

Nedjat, S., Montazeri, A., Holakouie, K., Mohammad, K., \& Majidzadeh, R. (2008). Psychometric properties of the Iranian interview-administered version of the World Health Organization's Quality of Life Questionnaire (WHOQOL-BREF): a population-based study. BMC Health Services Research, 8(1). http://dx.doi.org/10.1186/1472-6963-8-61

Oh, H. J., Ozkaya, E., \& Larose, R. (2014). How does online social networking enhance life satisfaction? The relationships among online supportive interaction, affect, perceived social support, sense of community, and life satisfaction. Computers in Human Behavior, 30, 69-78. http://dx.doi.org/10.1016/j.chb.2013.07.053

Onyx, J., \& Bullen, P. (2000). Measuring social capital in five communities. The journal of applied behavioral science, 36, 23-42. http://dx.doi.org/10.1177/0021886300361002

Organization, W. H. (1996). WHOQOL-BREF: introduction, administration, scoring and generic version of the assessment: field trial version, December 1996.

Pearce, N., \& Davey Smith, G. (2003). Is social capital the key to inequalities in health? American journal of public health, 93, 122-129. http://dx.doi.org/10.2105/AJPH.93.1.122

Poorafkary, N. (2012). Evaluation of relationship between mental health and academic growth of students (casestudy: university students in the Faculty of Literature and Humanities). quarterly Professional Journal of Social Sciences, 6, 167-186.

Rahmani, A., \& Sohrabi, S. (2012). The Sociological Study of the Relationship Between Life Quality And Social Capital Journal of Studies of Socio-Cultural Development, 1, 157-175.

Rajabi, G. N., Ghasemi, S. R., Reshadat, S., \& Rajabi, S. (2014). The Relationship Between Social Capital and Health-Related Quality of Life among Teachers, Journal of Zanjan University of Medical Sciences and Health Services, 21, 95-107.

Razavizadeh, N., Bahnani, M., \& Yousofi, A. (2013). Social Capital and Mental Health among Students of Ferdowsi University of Mashhad. Journal of Social Sciences (Biannual), 9, 25-51.

Rezvani, M., Gilaninia, S., \& Mousavian, S. J. (2011). Strategic planning: A tool for managing organizations in competitive environments. Australian Journal of Basic and Applied Sciences, 5, 1537-1546.

Rezvani, M. R., \& Mansourian, H. (2008). Assessing the quality of life: A review of concepts, indices and models, and 
presentation of a proposed model for rural areas.

Richardson, J. G. (1986). Handbook of Theory and Research for the Sociology of Education, Greenwood Publishing Group.

Rimaz, S., Dastoorpoor, M., Vesali, S., Salepour, N., Nedjat, S., Sadeghi, M. \& Khoei, E. M. (2015). Investigation of relationship between social capital and quality of life in female headed families. Medical Journal of The Islamic Republic of Iran, 29, 270. http://dx.doi.org/10.5539/gjhs.v6n6p261

Rimaz, S., Mohammad, K., Dastoorpoor, M., Jamshidi, E., \& Majdzadeh, R. (2014). Investigation of relationship between social capital and quality of life in multiple sclerosis patients. Global journal of health science, 6, 261.

Roslan, A., Russayani, I., \& Norazam, A. (2010). The impact of social capital on quality of life: evidence from Malaysia. European Journal of Economics, Finance and Administrative Sciences, 4, 113-122.

Scheffler, R. M., Brown, T. T., Syme, L., Kawachi, I., Tolstykh, I., \& Iribarren, C. (2008). Community-level social capital and recurrence of acute coronary syndrome. Social science \& medicine, 66, 1603-1613. http://dx.doi.org/10.1016/j.socscimed.2007.12.007

Shakhi, K., Hossein, P. D., Maharloo, H. R., Zahiri, M., \& Haghighi, Z. M. H. (2013). Students' Views about the Educational Quality of Health Services Management Department in AJUMS

Sharifiyan, A., \& Fotovat, H. (2012). Social Capital and Quality of Life Case Study of Shiraz University Students (Pardis Branch). Social Development \& Welfare Planing, 8, 153-188.

Soltani, T., \& Jamali , M. (2008). Investigating of the Relationship between Social Capital and Mental Health Participants: Students of the Social Sciences Department, Shiraz University. Quarterly Journal of Management and Development Process, 21, 108-121.

Tavakol, M., Moidfar, S., \& Maghsudi, S. (2012). Relationship between Social Capital and Mental Health of Married Couples in Kerman. Iranian Journal of Social Problems, 2, 173-202.

Zamanzadeh, V., Heidarzadeh, M., Oshvandi, K., \& Lakdizaji, S. (2007). Relationship between Quality of Life and Social Support in Hemodialysis Patients in Imam Khomeini and Sina Educational Hospitals of Tabriz University of Medical Sciences. Medical Journal of Tabriz University of Medical Science \& Health Service, 29, 49-54.

Zarabi, A., \& Shahivandi, A. (2010). An Analysis of distribution of economic development indices in Iran provinces. Geography and Environmental Planning, 21, 17-32.

\section{(cc) BY}

This work is licensed under a Creative Commons Attribution 3.0 License. 